\title{
O potencial do galego como elemento integrante da estratexia empresarial
}

\author{
Anxo Calvo Silvosa \\ Universidade da Coruña
}

\begin{abstract}
Resumo:
Este artigo pretende vincular o uso da lingua á estratexia empresarial desde a súa mesma concepción. Actualmente, o galego é unha lingua de uso habitual na empresa, mais non é a "lingua visíbel" das relacións que se producen entre os diferentes grupos de interese que existen arredor da empresa. Logo da revisión do concepto de estratexia, pódese afirmar que esta é un instrumento para inserir a empresa no seu contorno. A cuestión lingüística pode formar parte das estratexias corporativas, competitivas e funcionais e contribuír de forma clara ao incremento do valor da empresa. Na realidade empresarial actual, o uso da lingua galega axuda o reforzamento de estratexias de diferenciación pola calidade e pola asunción da imaxe de Galiza nos produtos e nos servizos. Tamén se relaciona o uso do galego nas empresas galegas coa súa responsabilidade social corporativa nun contexto onde desde o mundo empresarial cómpre dar pasos cara á normalización desta lingua.
\end{abstract}

\section{Palabras chave:}

Estratexia, responsabilidade social, normalización lingüística.

\begin{abstract}
:
The aim of this paper is to link the use of the Galician language to the corporate strategy from its origin in order to achieve the main objectives of the firm. Nowadays, Galician is a common used language in firm relationships. However, it can not be considered as the "visible language" of the different relationships among the stakeholders in the firm. After analyzing the concept of strategy, we can say that strategy is a useful tool to insert the firm in its environment. The linguistic subject could be part of the corporate, competitive and functional strategies and contribute to increase the value of the firm. Presently, the use of Galician by the firm can strengthen its option to make itself different from its competitors because it is linked to a higher level of quality and to the image of Galician product our service. Given that the process of linguistic normalization of Galician needs make progress in the business realm, It is also connected to the Social Responsibility of the Firm.
\end{abstract}

Key words:

Strategy, Social Responsibility, linguistic normalization. 


\section{Introdución}

Unha das cuestións máis relevantes nos procesos de normalización lingüística é a extensión do uso da lingua minorizada a todos os ámbitos de relación que existen na sociedade, tanto nos estritamente privados como nos públicos. En Galiza, é evidente que, a pesar de todos os problemas e pexas que o proceso normalizador tivo desde as súas orixes nos anos oitenta do pasado século, a lingua galega experimentou un considerábel avanzo nos usos que máis tiñan que ver coa esfera pública: administracións (autonómica e municipal) e ensino, principalmente. Porén, non se pode estender esta afirmación aos ámbitos onde a actuación das diferentes administracións fica máis diluída ou desaparece case de maneira absoluta. Un bo exemplo do que podería ser un ámbito escasamente normalizado é o mundo da empresa, onde os avanzos do galego dependen de actitudes de persoas concretas con peso na organización que, na maior parte dos casos, actúan con grandes doses de voluntarismo e case sempre coa incomprensión do resto dos axentes empresariais.

En calquera caso, parece importante salientarmos que o futuro da lingua non depende só dos avanzos que se conseguiren no eido cultural, educativo ou das administracións públicas. O mundo da economía (mercados de bens e servizos, de traballo, financeiros etc.), das relacións laborais e das diferentes funcións empresariais (organización, loxística, comercialización, finanzas...) son ámbitos en que se está a xogar a normalización lingüística real da sociedade por seren absolutamente fundamentais e indispensábeis para acadarmos colectivamente este obxectivo. Poderíase afirmar categoricamente que o galego non estará normalizado até que sexa "normal" en todos os niveis internos da empresa e nas relacións que esta mantén co seu contorno. Dito doutro xeito, nun país lingüisticamente normalizado, nas empresas emprégase tanto no plano oral como no escrito a lingua propia dese país. Calquera observador pode decatarse de que a situación en Galiza está a día de hoxe moi afastada desa situación a que se quere camiñar coas políticas de normalización do galego.

O propósito deste traballo é profundar nesta realidade, non desde un punto de vista filolóxico ou sociolingüístico, senón desde unha óptica de xestión empresarial. Para isto, comezarase por empregar o concepto de estratexia corporativa, central na dirección de empresas, para especular en que medida a "cuestión da lingua" pode entrar nun esquema de xestión próximo ao mundo da empresa. Logo disto, vincúlase o comportamento das empresas a respecto da lingua coa súa responsabilidade social empresarial para, finalmente, rematar cunha breve diagnose de como se atopa o galego no mundo empresarial suxerida polos redactores do Plan Xeral de Normalización da Lingua Galega (Xunta de Galicia 2005) -en adiante PXNLG-. 


\section{A lingua e a estratexia das empresas}

Para desenvolver cumpridamente este aspecto, cómpre asumirmos desde o comezo que as empresas son sistemas sociotécnicos de carácter aberto. Isto implica que na empresa existe un sistema social -evidentemente integrado por persoas- que actúa sobre un sistema técnico (maquinaria, mercadorías, instalacións etc.). Alén disto, por ser un sistema aberto, a empresa está constantemente a manter relacións co seu contorno para conseguir del todo canto precisa (materias primas, recursos financeiros, servizos, man de obra etc.) e poder acadar o seu obxectivo central (crear valor para os seus propietarios ou, expresado noutros termos diferentes, incrementar o seu valor no mercado) e para lle trasladar un conxunto heteroxéneo de outputs (produtos e servizos, información, rendas etc.).

É evidente que o contorno xenérico está integrado por un conxunto diverso de factores (económicos, político-legais, tecnolóxicos e sociais) que nun momento determinado afectan o conxunto de empresas que operan nun lugar concreto. No entanto, para avanzar nesta reflexión, cómpre pormos a atención no que se denomina o "contorno específico" da organización, isto é, o conxunto de grupos de interese que se ven afectados dun ou doutro xeito pola existencia e a acción da empresa, cun interese lexítimo, directo ou indirecto, pola marcha desta e que asemade inflúen na consecución dos obxectivos marcados e na súa mesma sobrevivencia (AECA 2004). A modo de exemplo, podemos incluír no contorno específico (Ilustración 1) os provedores, clientes, fornecedores de recursos financeiros (tanto propietarios como acredores), competidores, administracións públicas e outros grupos sociais (asociacións empresariais, sindicais etc.).

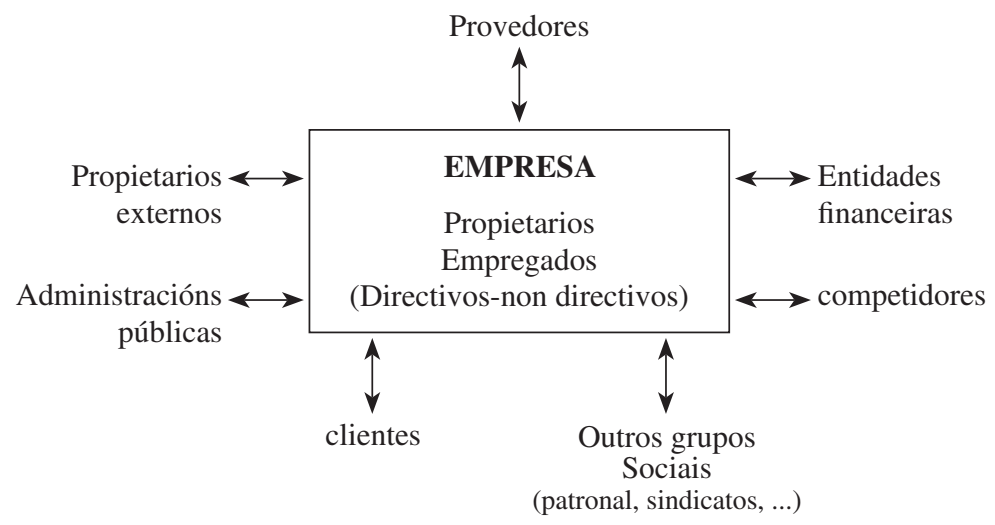

Ilustración 1: O contorno específico da empresa 
Dentro da empresa, os grupos de interese internos (empregados -directivos e non directivos- e propietarios) desenvolven cometidos específicos e definen un sistema de relacións internas que lle dan á realidade empresarial os trazos necesarios para ser considerada coma unha "organización": existe un elemento humano, unha división de funcións e de actividades ou tarefas, un sistema de comunicacións e un grupo de control. Feito este achegamento simple e resumido, xorde unha pregunta de maneira inmediata: en que lingua se verifican todas estas relacións externas e internas nunha empresa galega ou localizada en Galiza?

A observación da realidade permite afirmar que o galego está presente en grande parte das comunicacións que se realizan no interior da empresa e naquelas que se manteñen entre esta e o seu contorno. Porén, igualmente podería dicirse que, á diferenza do español, a lingua galega é unha lingua invisíbel. A proximidade que existe entre o galego e o español e o coñecemento que practicamente toda a poboación de Galiza ten de ambos os dous idiomas fai que oralmente sexan frecuentes as conversas en galego ou de carácter bilingüe, onde os participantes se expresan indistintamente nas dúas linguas. Nesta dinámica, o galego adoita levar a peor parte, porque cando se recolle por escrito o contido de tales conversas (documentación empresarial: contratos, facturas, ***albarás, rexistros internos etc.), a única lingua que se visualiza é o español. A pesar de o idioma galego existir no proceso económico e mesmo que ás veces poida ser predominante no nivel oral, pódese asegurar que nas grandes operacións económicas e nas grandes empresas só é visíbel o español, e o galego non se percibe en absoluto.

Asumindo que existe unha grande diversidade de empresas, no PXNLG faise unha análise da situación da lingua en función do ámbito xeográfico en que operan, do tipo de cliente e das relacións que manteñen á súa vez con outras entidades. Neste sentido, obsérvase que a amplitude de ámbito de actuación contribúe a que o galego se invisibilice, aínda que sexa a lingua que fale a maioría dos seus traballadores dentro dos procesos produtivos. Cando a empresa desenvolver actividades fóra de Galiza, a lingua galega fica practicamente desaparecida da escrita e da sinalización da sinatura. Neste sentido, o proceso de globalización actúa sen dúbida contra a lingua feble até a facer desaparecer das súas relacións comerciais, xurídicas e administrativas.

Cando a clientela da empresa for a usuaria final dos seus produtos ou servizos (comercio e servizos financeiros, esencialmente), esta pode consentir ou admitir certa visualización da lingua. Ora ben, se a empresa desenvolver un produto intermedio ou un servizo destinado a outra empresa, o galego volve manifestar claramente a súa debilidade e desaparece dos rexistros escritos e da comunicación oficial.

Se se parte do carácter sistémico da empresa e se admite a presenza nela de grupos de interese como os sinalados con anterioridade (tanto internos como externos), 
poderíase formular a seguinte proposición: a lingua visíbel da empresa, de igual xeito que o que acontece cos seus obxectivos, será a lingua do(s) grupo(s) con maior poder no seo da empresa. Deseguido, xorden dúas cuestións derivadas desta afirmación: a primeira é se existen diferenzas entre empresas galegas e non galegas ou, dito doutro modo, en que se manifesta a galeguidade dunha empresa?; a segunda pregunta interroga sobre se existen comportamentos lingüísticos diferenciados en función dos diferentes grupos que concorren na empresa (hai relación entre nivel de formación e usos lingüísticos ou entre nivel económico e prácticas idiomáticas?).

Na realidade política e empresarial actual, estas preguntas gañan grande importancia por canto existen empresas que se presentan perante a administración galega de maneira expresa e declarada como "nitidamente galegas" ao entenderen que, á diferenza do que acontecía no pasado, este carácter pode facilitarlles a relación co nacionalismo gobernante en Galiza. Non é doado responder a que é unha empresa galega, xa que existen diferentes variábeis en función das cales se podería valorar o intanxíbeis "galeguidade" dunha organización: unha empresa galega sería, talvez, aquela cuxos propietarios son galegos? Ou cuxos directivos son galegos? Acaso cuxos traballadores son maioritariamente galegos? Ou cuxa clientela está localizada principalmente en Galiza? Podería ser aquela, igualmente, cuxos centros de decisión estivesen en Galiza? Ou cuxo domicilio fiscal está en territorio galego e tributa dentro de Galiza? Ou, inclusivemente, non se podería pensar nunha combinación de todo isto?

\section{O concepto de estratexia empresarial}

Talvez cumpra fuxirmos de respostas apresadas e pouco reflexivas e achegarmos algún concepto teórico procedente do ámbito da dirección de empresas que contribúa a resolver non tanto as "cuestións ontolóxicas", importantes certamente nun plano de debate político e identitario, senón como incorporar dunha forma plenamente inserida na lóxica empresarial o problema real e identificado consistente en que o idioma galego, a pesar de que exista na vida económica, non é visíbel nas relacións internas nin externas da empresa.

Nesta dirección, o concepto de estratexia empresarial pode ser de moita utilidade. Porén, non existe unha definición única nin sequera totalmente aceptada no mundo empresarial ou no académico. Os diferentes intentos por precisar este amplo concepto fan referencia ás relacións existentes entre o interior da empresa co seu contorno, ao vínculo entre as políticas e as metas concretas para acadar obxectivos máis amplos, á forma que ten a organización para se introducir, ficar e dominar nun mercado etc. 
O concepto de estratexia procede orixinalmente do ámbito militar e incorpórase por primeira vez ao campo económico e académico da man de Von Neumann e Morgenstern en 1944 na súa aplicación á teoría de xogos. Na súa orixe, o concepto de estratexia está estreitamente vinculado ao de competición ou actuación fronte a un adversario. $\mathrm{O}$ grande desenvolvemento do concepto de estratexia empresarial prodúcese na década dos anos sesenta do século XX, ao se realizaren moitas achegas teóricas sobre esta materia que, en grande medida, xeraron confusión ao usaren o mesmo termo para faceren referencia a significados diversos. Porén, mantense a idea de competición e de acción fronte ao contorno.

Na literatura académico-empresarial existen dous enfoques principais para definir o contido da estratexia empresarial: o enfoque amplo e mais o restrito. O primeiro deles -amplo- vén propugnado pola escola de Harvard e inclúe o proceso de definición dos fins, obxectivos e metas. Nesta liña, cómpre salientar autores clásicos como Chandler (1962), que, sen distinguir entre estratexia e proceso para a súa formulación, entende que esta supón "a determinación das metas e obxectivos básicos dunha empresa no longo prazo, a adopción dos cursos de acción e a asignación dos recursos necesarios para a consecución de tales metas"; ou Andrews (1984), que sostén que a estratexia debe considerarse como "o patrón de decisións dunha compañía que determina e revela os seus obxectivos, fins ou metas, xera as principais liñas para seguir e os planos para seren acadadas as metas, e asemade define a amplitude do negocio que a compañía vai desenvolver, a clase de organización humana e económica que é ou pretende ser e a natureza da contribución económica e non económica que tenta facer aos seus accionistas, empregados, clientes e contorno...". Menguzzato / Renau (1984) resumen este enfoque amplo ao afirmaren que a estratexia empresarial "explicita os obxectivos xerais da empresa e os cursos de acción fundamentais, consonte os medios actuais e potenciais da empresa para lograr a inserción óptima desta no medio socioeconómico".

O enfoque restrito limita a estratexia aos medios usados para acadar uns determinados obxectivos. Nesta liña de pensamento, Hofer / Schendel (1978) entenden a estratexia como "o modelo fundamental de asignacións de recursos e interaccións co contorno, presentes e futuras, que indican como a organización vai cumprir os seus obxectivos". Seguindo con este ideal, Cuervo García (1975) delimita o contido do concepto como "o proceso a través do cal a empresa adapta os seus recursos ao marco externo e ás forzas internas en continua mudanza, tendo sempre presentes os obxectivos que quere acadar".

En definitiva, preténdese mostrar a estratexia empresarial como a ferramenta posta ao servizo da organización que, co obxectivo de achar a constante adaptación da empresa ao seu contorno e ás mudanzas que este presente, fai explícitas as grandes opcións que van determinar as decisións da empresa sobre actividades e estruturas da organización e que, en consecuencia, actúa como marco de referencia onde se 
deberán inscribir todas as accións que a empresa vai emprender nun período de tempo estabelecido.

A definición da estratexia está estreitamente vinculada á idea de manter posicións competitivas satisfactorias ou mesmo de melloralas no marco dun contorno concreto. Isto vén reforzar a cuestión de competencia e actuación fronte ao contorno. En consecuencia, a estratexia perseguirá, ao ser definida, a obtención de vantaxes competitivas, é dicir, características que a empresa poida e deba desenvolver para obter e/ou fortalecer unha posición vantaxosa fronte aos seus competidores. Esta reflexión supera o concepto de "empresa competente": a firma non só debe ser quen de traballar nunha actividade determinada, senón que deberá facelo de maneira máis eficaz e eficiente que o resto das empresas que concorren no seu mesmo mercado. Nesta liña, pode formularse unha definición de estratexia como comportamento polo cal unha corporación é quen de se diferenciar positivamente dos seus competidores, a usar os puntos fortes relativos da corporación para satisfacer máis acaidamente as necesidades do consumidor. Para Ansoff (1976), a estratexia representa "a dialéctica da empresa co seu contorno" no sentido de que todos os obxectivos empresariais e todas as accións se dirixirán de maneira inexorábel á consecución dunha vantaxe competitiva sustentábel. Tabatoni / Jarniou (1975) salientan o papel de nexo que a estratexia estabelece entre a empresa e o contorno ao definila como "o conxunto de decisións que determinan a coherencia das iniciativas e reaccións da empresa fronte ao seu contorno".

En resumo, a través da estratexia, a empresa é capaz de se inserir no seu contorno de maneira eficaz e eficiente, de se desenvolver nel e de cumprir a misión que ten encomendada desde a súa xénese. Neste sentido, a estratexia define a liña de actuación da firma ao concretar cales son os fins que persegue, os medios que lle cómpren e as actuacións que debe realizar para garantir a súa sobrevivencia e acadar os seus obxectivos. Por tanto, ao falar de estratexia, estase facendo referencia a un patrón de comportamento da empresa que lle permite determinar que clase de organización é ou pretende ser e en que clase de negocios está ou quere estar.

Resulta bastante claro que tanto a formulación da estratexia (definición de fins, determinación dos medios necesarios e deseño dos cursos de actuación) como a implantación desta precisan necesariamente da elección dunha lingua vehicular. Esta escolla manifesta, nun país anómalo desde o punto de vista lingüístico como é Galiza, a opción da empresa por perpetuar a situación actual ou por mudala para lle dar maior visibilidade ao galego. Esta elección, por ser a realidade galega como é, devén absolutamente clave e con consecuencias directas na determinación da misión, visión e valores corporativos. O feito de unha empresa optar polo galego na formulación e na implantación da súa estratexia reflicte indubitabelmente que esa organización manifesta unha sensibilidade pola realidade lingüística e cultural do territorio onde vai desenvolver a súa actividade produtiva e comercial e expresa a súa posición a prol da superación do conflito idiomático actual para facer do galego 
unha lingua normalizada no seu ámbito territorial propio. Da mesma maneira, a elección doutra lingua, nomeadamente o español, debe ser considerado un feito non neutral, xa que contribúe a manter o galego na situación minorizada e de invisibilidade a que se fixo referencia con anterioridade.

Se o galego se fixese presente na determinación da misión, se formase parte do modelo de empresa a través da visión e se incorporase aos valores corporativos, resultaría altamente probábel que o galego se convertese na lingua visíbel da formulación dos obxectivos xerais, tácticos e operacionais e, seguindo coa coherencia, incorporalo ao esquema da estratexia nos seus tres niveis (Ilustración 2): global ou de empresa ${ }^{1}$, competitivo $^{2}$ e funcional ${ }^{3}$. Neste punto, xa se estaría nunha situación caracterizada pola presenza na lingua galega na reflexión de futuro da empresa (planificación, esencialmente) e na vida cotiá da organización (nos seus procesos, na súa política comercial -publicidade, forza de vendas, relacións públicas-, na súas comunicacións internas etc.).

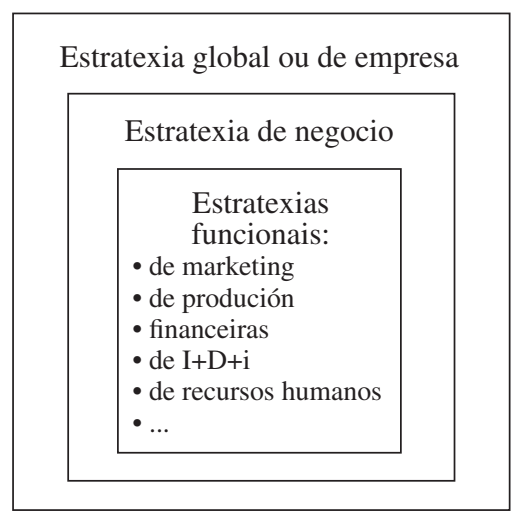

Ilustración 2: Os niveis de estratexia

1 No nivel de estratexia global ou de empresa, decídese en que negocios participa a empresa e cal é a asignación de recursos a cada un dos negocios que integran o seu portafolio.

2 No nivel de estratexia competitiva ou de negocio, a empresa decide, para cada un dos negocios que integran o seu portafolio ou ámbito de actuación, como vai competir: buscando vantaxes competitivas en custos (liderado en custos) ou en diferenciación, orientando a súa actuación ao conxunto do mercado ou a un grupo reducido de consumidores etc.

3 Unha vez elixida o forma de competir en cada negocio (nivel de estratexia competitiva ou de negocios), a empresa define como actuar en cada unha das funcións empresariais básicas necesarias para materializar a súa opción polo liderado en custos, diferenciación, focalización etc. As estratexias funcionais clásicas son as de produción (decisións de dimensión ou escala, localización, deseño de procesos de produción etc.), de comercialización (decisións sobre o produto, prezo, distribución e comunicación), de Investigación, Desenvolvemento e Innovación (interiorizar ou externalizar esta función), de recursos humanos (captación, formación, promoción, retribución etc.)... 


\section{A Responsabilidade Social da Empresa}

Como consecuencia de todo o anterior, a decisión de que a lingua galega estea presente na formulación e na implantación da estratexia empresarial en todos os seus niveis amosa o compromiso da empresa co desenvolvemento integral da sociedade galega, non só desde o punto de vista económico, mais tamén desde unha óptica social e de patrimonio cultural. Esta idea ten relación directa co concepto de desenvolvemento sustentábel. Este pretende conciliar o crecemento económico coa preservación do ambiente e coa cohesión e o benestar sociais (Ilustración 3). Parece claro que, para conseguir avanzos reais cara a este equilibrio, teñen que se implicar de forma clara tanto as administracións públicas, a través de políticas activas nesta dirección, como o conxunto da sociedade, onde se atopan evidentemente as empresas.

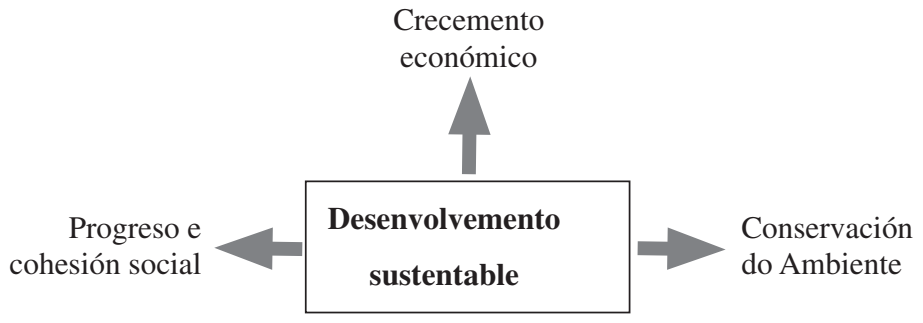

Ilustración 3: Piares do desenvolvemento sustentábel.

Neste contexto emerxe con forza unha ferramenta útil e doadamente inseríbel na reflexión estratéxica e na práctica cotiá das sinaturas: a responsabilidade social da empresa (RSE).

Dentro da Unión Europea, a RSE incorporouse á axenda de temas centrais e foi obxecto de múltiplos pronunciamentos a partir de 2000 (Consello Europeo de Lisboa e Cumio de Niza en 2000, Libro Verde en 2001, Comunicacións de 2002 e 2006 etc). A Comisión Europea (2006) define a RSE como "a integración voluntaria, por parte das empresas, das preocupacións sociais e ambientais nas súas operacións empresariais e nas súas relacións cos seus interlocutores". Está claro que a RSE, ao incorporar un amplo abano de obrigas e compromisos de natureza normativa e ética e ser totalmente voluntaria, implica ir alén do simple cumprimento da normativa legal estabelecida e da obtención de resultados económicos no curto prazo. Supón unha orientación de categoría estratéxica que afecta toda a toma de decisións e as operacións do conxunto da organización, creando valor no longo prazo e contribuíndo de maneira significativa á obtención de vantaxes competitivas duradeiras (AECA 2004). 
En Galiza, un sinal de ser "empresa socialmente responsábel” é precisamente o participar no proceso de normalización lingüística do idioma galego por medio da incorporación deste á estratexia da organización. Actualmente, non existe unha normativa en materia de lingua que sexa de obrigado cumprimento para o sector empresarial privado. Expresado doutro xeito, xa que unha empresa pode actuar en Galiza (fornecerse de materias primas, transformalas, comercializar produtos, contratar persoal, realizar contratos...) cun total esquecemento da lingua galega, todo o que se faga neste ámbito é estritamente voluntario. Igualmente, pódese afirmar que, na actualidade, actuar como unha empresa comprometida co galego non é doado por canto que existe outra lingua -o español- absolutamente omnipresente e sobre a que existe normativa que a protexe e lle dá un carácter hexemónico, cando non absoluto no mundo da empresa. En consecuencia, o uso público da lingua galega por parte das empresas é sinal de ser empresa socialmente responsábel ao reflectir de maneira expresa un compromiso coa cultura, co patrimonio lingüístico do pobo galego.

Alén disto, a sociedade recompensa estas actitudes: as empresas adoitan acadar unha imaxe positiva ou de prestixio como "empresa galega" e normalmente os consumidores vinculan a súa actuación -e incluso os seus produtos e servizos- a un maior nivel de calidade. En definitiva, e como consecuencia de ser Galiza un país non normalizado desde o punto de vista idiomático, o emprego do galego reforza as estratexias de diferenciación das empresas, créalles vantaxes competitivas duradeiras, contribúe a mellorar os resultados empresariais e, como consecuencia, incrementar o valor de mercado da empresa.

\section{A normalización lingüística do galego no mundo da Economía segundo o PXNLG}

Polo tanto, o compromiso lingüístico das empresas ten un encaixe correcto dentro do razoamento empresarial e contribúe a que se acaden os obxectivos últimos de creación de valor e mesmo de sobrevivencia. Neste sentido, o PXNLG realiza unha rigorosa análise da situación do idioma no ámbito da Economía, formula uns obxectivos xerais e, con posterioridade, propón para cinco áreas específicas (industria, comercio, cooperativismo, banca e traballo) obxectivos específicos e medidas concretas.

Cómpre salientarmos que entre os puntos fortes identificados, o PXNLG salienta a importante presenza do galego en todo o territorio galego e, con maior ou menor intensidade, en todos os grupos de idade, o que o converte nunha lingua axeitada para a relación laboral e comercial. Alén disto, detecta que os índices de rexeitamento ao uso empresarial do galego son baixos e, como consecuencia, créase un clima 
favorábel para a publicidade en lingua galega. Por outra banda, a proximidade lingüística do galego co portugués e mais co castelán favorece a intelixibilidade da lingua galega na relación comercial tanto dentro de Galiza como cos países veciños.

Polo contrario, tamén se identifícan puntos febles. Entre os máis preocupantes, poderíase indicar que existe unha fractura da cadea lingüística nos cadros técnicos tanto por se teren que relacionar con empresas, provedores e clientes que non teñen por que coñecer o galego, como pola case total inexistencia de documentación técnica en galego, circunstancia que os fai sentir inseguros neste idioma. Outro problema é o que se deriva de que unha parte importante dos empresarios perciban que o galego é unha lingua non necesaria e, polo tanto, prescindíbel para as súas actividades ou que está marcada como lingua dun sector minoritario (cultura e política) ou de menor poder adquisitivo. A isto pódese engadir certo medo a se posicionaren respecto do galego, pola posibilidade de causar algún rexeitamento en sectores ou clientes, temor que, segundo a propia reflexión formulada no PXNLG, é infundado. Isto, dalgún xeito, provoca dúbidas de que na relación custo/beneficio a opción polo galego sexa rendíbel para unha empresa.

\section{Conclusións}

A modo de conclusión, pódese afirmar que a situación da lingua galega na empresa reflicte en grande medida cal é a situación deste idioma no conxunto da sociedade: existe como lingua de relación no ámbito oral; porén, non é visíbel nos aspectos máis formais ou transcendentes da vida da organización. No binomio galego-español, claramente é o idioma feble e, polo tanto, minorizado nas relacións que a empresa mantén tanto no seu interior como cos grupos de interese con que se relaciona no seu contorno.

A normalización efectiva da lingua galega no mundo empresarial, cuxo resultado directo debe ser a súa visualización, pasa necesariamente por incorporar o "factor idiomático" na columna vertebral da actuación da empresa, é dicir, na súa estratexia. Isto vai garantir a integración da lingua na súa misión, visión e valores e a presenza visíbel en todos os seus ámbitos de acción. Dado que a través da estratexia a empresa procura inserirse, desenvolverse e sobrevivir no contorno en que opera, existen datos obxectivos (presenza da lingua en todo o territorio, amplo coñecemento de practicamente toda a poboación do galego, baixos índices de rexeitamento desta lingua no conxunto da sociedade etc.) que, alén de avalar, aconsellan que as organizacións empresariais fagan un uso completo -oral e escrito- do galego nas súas relacións cos grupos de interese, tanto internos como externos, cos que manteñen relacións. 
Nun contexto onde non existen normas que apoian a normalización do galego no ámbito empresarial e onde, como consecuencia, toda actuación é voluntaria, a presenza do galego no diferentes niveis da estratexia (corporativo, competitivo e funcional) reforza a imaxe da empresa como "socialmente responsábel". Nunha situación social e lingüística como a que no momento actual existe en Galiza, tal circunstancia, lonxe de constituír unha pexa para a consecución dos seus obxectivos, actúa intensificando positivamente a diferenciación dentro do mercado como empresa comprometida cos valores culturais propios do País. Esta boa imaxe remata xeralmente por crear unha percepción de calidade que afecta os produtos e servizos que constitúen o obxecto da actuación empresarial. Loxicamente, o emprego da lingua galega, ao crear este intanxíbel, redunda nun incremento do valor da empresa, obxectivo final da xestión.

\section{Referencias bibliográficas}

AECA (1999): Estrategia Empresarial. Modelo Dinámico del Proceso Estratégico, Documentos AECA, Principios de Organización y Sistemas, $n^{\circ} 9$.

AECA (2004): Marco Conceptual da Responsabilidade Social Corporativa, Documentos AECA, Responsabilidad Social Corporativa, $\mathrm{n}^{\circ} 1$.

Andrews, K. R. (1984): El concepto de Estrategia de la Empresa (Barcelona: Orbis).

Ansoff, H. I. (1976): La Estrategia de la Empresa (Pamplona: EUNSA).

Chandler, A. (1962): Strategy and Structure (New York: MIT Press).

Comisión Europea (2006): Comunicación de la Comisión al Parlamento Europeo, al Consejo y al Comité Económico y Social Europeo. Poner en práctica la asociación para el crecimiento y el empleo: hacer de Europa un polo de excelencia de la responsabilidad social de las empresas. Bruxelas, 22.03.2006, COM, 136 Final (Bruxelas: Comisión de las Comunidades Europeas).

Cuervo García, A. (1975): "La planificación en el proceso de decisión en la empresa", Revista de Economía Política, 71: 141-190.

Hofer, C. W. / Schendel, D. E. (1978): Strategy Formulation: Analytical Concepts (Minnesota: West Publishing Co.).

Menguzzato, M. / Renau, J. J. (1984): "El planteamiento estratégico: una necesidad para la empresa de hoy", Actas del Primer Congrés d'Economia Valenciana (València: Generalitat Valenciana).

Tabatoni, P. / Jarniou, P. (1975): Les Systémes de Gestión. Politiques et Structures (Paris: PUF).

Xunta de Galicia (2005): Plan Xeral de Normalización da Lingua Galega (Santiago de Compostela: Consellaría de Educación e Ordenación Universitaria. Dirección Xeral de Política Lingüística). 